\title{
A IMPORTÂNCIA DA FAMÍLIA, ESCOLA E COMUNIDADE NA FORMAÇÃO DO ETHOS NO OESTE DE SANTA CATARINA
}

\author{
THE IMPORTANCE OF FAMILY, SCHOOL AND \\ COMMUNITY IN THE ETHOS FORMATION IN \\ WESTERN SANTA CATARINA
}

\author{
Paulino Eidt ${ }^{*}$ \\ Anderson Luiz Tedesco ${ }^{* *}$
}

\begin{abstract}
RESUMO
Este artigo objetiva compreender a importância da família, escola e comunidade na constituição do ethos dos povos pré-capitalistas da Região Oeste de Santa Catarina e as transformações societárias decorrentes quando da ocupação do território, no início do século XX, pelos migrantes de descendência europeia. Sabe-se que o ethos se estabelece entre a família, a escola e a comunidade educadora como exigência universal no constituir o exercício da práxis no âmbito do trabalho, da cultura, da política e da convivência social. Trata-se de um estudo teórico sobre a relação dialógica estabelecida entre a família, escola e a comunidade dos povos indígenas e mais tarde de descendência europeia. Constatou-se que tanto os povos pré-capitalistas da região quanto os povos das frentes abrigaram um modus vivendi, sem a presença do Estado e mantiveram num modelo comunitário coeso, holístico e centrípeto. A partir da Segunda metade do Século XX, toda a mesorregião de Santa Catarina passou sob a égide do controle do Estado. Por conseguinte, a presença estatal, o nacionalismo, a entrada mais agressiva do capitalismo destituíram aquele primeiro ethos, impondo relações sociais mais verticalizadas sem, contudo, eliminar, na versão de Zygmunt Bauman, os paroquialismos e comunitarismos, que passam a ter novas formas.
\end{abstract}

Palavras-chave: Comunidade. Escola. Educação. Família.

\begin{abstract}
This article objective understand the importance of family, school and community in the constitution of the ethos of the pre capitalists people in the Western region in Santa Catarina and the societal transformations deriving from the occupation of the territory in the initiation of twentieth century, by migrants of European posterity. We know that the ethos established between the family, school and the educating community as a universal requirement to constitute exercise of práxis at the work, culture, politics and sociability. It is a theoretical study about the dialectical relationship established between the family, school and community of indigenous people and late of European posterity. It was found that both the people of the regions pre capitalists as the people of the fronts shelter a
\end{abstract}

\footnotetext{
"Doutor em Ciências Sociais pela Pontifícia Universidade Católica de São Paulo - PUCSP. Professor do Programa de Mestrado em Educação da Universidade do Oeste de Santa Catarina.

${ }^{*}$ Doutorando em Filosofia pela Pontifícia Universidade Católica do Paraná - PUCPR. Professor da Universidade do Oeste de Santa Catarina e da Celer Faculdades
} 
modus Vivendi, without the presence of the state and maintained a community model cohesive holistic and centripetal. From the second half of the twentieth century all the middle region of Santa Catarina, passed under the aegis of state control. Thus, the state-owned presence, the nationalism, the aggressive entry of capitalism dismissed that first ethos, imposing social relations verticalized without eliminating, in the version of Zygmunt Bauman, the parochialism and communitarianism that now have new ways.

Keywords: Community. School. Education. Family.

\section{Introdução}

Ao considerar como preocupações históricas, filosóficas e sociológicas as compreensões acerca da formação do ethos constituído no meio Oeste Catarinense, buscou-se por ora, refletir sobre a construção da identidade dos povos pré-capitalistas, considerados então os nativos da época na Região Oeste de Santa Catarina e, denominados como: kaingangs, Xokleng e Tupis-guaranis. Posteriormente, acrescem-se a esses grupos indígenas os Caboclos.

Seguindo nas compreensões dos primeiros habitantes das terras do Oeste Catarinense, veemse mais tarde, com certa tenacidade, as ocupações da região por migrantes de descendência europeia e a formação do ethos comunitário como condição necessária para a sobrevivência em meio à floresta. Ora, essas ilhas de ocupações, atormentadas e extasiadas com epidemias, tiveram de conjugar esforços que, necessariamente, passavam pela solidariedade horizontal. A solidariedade constituiu uma blindagem contra a insegurança e a instabilidade e, em última instância, condição necessária para a sobrevivência do próprio tecido social. Presos ao mundo natural e linear, e avesso ao moderno, seus personagens encontraram um campo privilegiado para práticas coletivas, solidárias e coesas. Comunidades organizadas na pequena propriedade de subsistência, utilização da mão-de-obra familiar acentuando espírito comunitário com ampliação e aprofundamento de valores como igualdade e solidariedade. Portanto, acentuou-se a compreensão de que eram comunidades forjadas em valores de igualdade, solidariedade e espiritualidade na formação do ethos.

Por fim, a reflexão se atém ao período mais recente da Região (final do século XX e primeira década do século XXI), quando o espaço regional é incorporado aos circuitos internacionais da econo- mia por meio do processo de agroindustrialização. Surgem novos atores, novas relações e novas interdependências forjadas pelo mundo da mercadoria e das tecnologias.

\section{Panorama conceitual sob a perspectiva histórica, filosófica e sociológica do Oeste catarinense}

Ao partir de um viés histórico, filosófico e sociológico acerca das compreensões terminológicas da comunidade, família e escola na formação do ethos no Oeste de Santa Catarina - deparamo-nos, num primeiro momento, com as definições conceituais: o que viria a ser o ethos? Tal compreensão vem como pressuposto básico para entender a formação genuína dos povos nativos do Oeste catarinense na figura dos Kaingang, Xokleng e dos Tupis-guaranis e, posteriormente, dos Caboclos.

Deste modo, constituir algumas reflexões acerca da comunidade no Oeste catarinense tornouse prioritário, antes de tudo, a pensar na formação fisionômica do ethos nessa região do estado de Santa Catarina. Por conseguinte, sua primeira complexidade apresenta-se na própria definição conceitual de ethos, que curiosamente, é um termo de origem grega podendo ser traduzido na perspectiva de morada do ser ou abrigo de animais. Desse modo, na concepção de Streck (2006, p. 96) esse "conceito éthos remete tanto a uma dimensão individual quanto à dimensão política e comunitária”. Por isso, se assemelha às reflexões de Boff ao afirmar que justamente esse ethos "significa a morada, o abrigo permanente, seja dos animais (estábulos), seja dos seres humanos (casa)" (2003, p. 28).

Tornando-se, deste modo, mais clara essa conjectura do ethos como casa do ser humano, por ele se configurar nas relações humanas, a própria 
organização desse coletivo - a comunidade. Isso pode ser evidenciado a partir do que Hermann (2008, p. 26) afirma:

Há, certamente, um mínimo de normas morais, validadas intersubjetivamente, que constituem nosso ethos e sem as quais se torna muito difícil edificar a formação humana. O compartilhamento de valores e regras comuns permite projetar um mundo sob o qual se dá a base de nossas conversações. $\mathrm{O}$ reconhecimento dessa condição sob a qual se dá a experiência educativa não exclui, contudo, a necessária, vigilante e, às vezes, até impiedosa crítica, à qual devemos submeter todo tipo de normatividade e as crenças em que se apóiam.

Além dessas reflexões sobre o ethos como pressuposto básico na formação do coletivo, tem-se como aporte teórico um dos principais filósofos brasileiros, Henrique C. de Lima Vaz, por cuja teoria se aponta a fenomenologia do ethos e a Ética como sendo a ciência desse ethos, compreendida na perspectiva de entender o âmago cultural - aflorado no próprio ethos. Desse modo, pode-se pensar na estruturação fenomenológica do ethos no Oeste catarinense apresentado como "um fenômeno histórico-cultural dotado de evidência imediata e impondo-se à experiência do indivíduo tão logo este alcance a primeira idade da razão" (VAZ, 2002, p. 37).

Ora, o filósofo, instiga-nos a pensar nessa idade da razão como sendo um dos aspectos do modo como o ser humano age na comunidade e, sobretudo, como suas experiências são externadas. "Sabe-se que o linguajar e a conduta se sobressaem no agir Comunitário e, tornam-se basilares na intenção de constituir a "vida no bem" (eu zen) e, consequentemente, o agir segundo o bem" (eu prattein), do qual deriva a "vida melhor" ou "mais feliz" (eudaimonia) para o agente ético e a "excelência" ou virtude (arete) de seu agir e de seu ser "(VAZ, 2002, p. 38).

De toda sorte, esse processo constitui-se numa articulação profunda no âmago da comunidade, fato esse, oriundo nas primeiras comunidades nativas do Oeste catarinense, pois elas caracterizavam-se pelo espírito comunitário, pelos laços da igualdade e da solidariedade. Como diria Vaz (2004, p. 11), é a partir da "transformação da physis (natureza) através da práxis (ação humana)" e, somando forças argumentativas nas palavras de Woloszyn $(2007$, p. 2), que se implantou um cultivar solidário de subsistência. Tal processo se deu com o "cultivo do feijão, do amendoim, do arroz, sobretudo da mandioca e do milho, que tinham lugar de destaque na horticultura cabocla", transformando a natureza como meio de sobrevivência dessas comunidades (Kaingang, Xokleng, Tupis-guaranis e, posteriormente, ds Caboclos). O mais significativo desse processo, segundo a historiadora, era a existência de pequenos estabelecimentos comerciais, as bodegas, onde se trocavam "produtos agrícolas como o fumo, o milho, o feijão, a erva-mate, etc. por sal, bebidas, querosene, pólvora, instrumentos de trabalho etc"- sem haver nesse momento histórico-cultural o desenvolvimento do Capitalismo propriamente dito.

Por isso essa experiência fenomenológica do ethos, anterior ao desenvolvimento do capitalismo, segue caracterizando-se inseparavelmente do social e do individual na perspectiva sócio-histórica; só existindo concretamente, "na práxis dos indivíduos; e é essa práxis que deixa seus traços nos documentos e testemunhos que nos permitem o acesso à fisionomia própria de um determinado ethos histórico" (VAZ, 2002, p.38). Ora, as primeiras comunidades nativas e caboclas no Oeste catarinense eram organizadas de modo a relacionar-se bem com a natureza, utilizando-a para a própria sobrevivência, sem interesse comercial, mesmo por que nem dinheiro existia, ou seja, construindo impressões de felicidade pela simplicidade de vida que tinham.

A partir dessas impressões históricas; filosóficas e sociológicas dos aspectos conceituais acerca da formação do ethos no Oeste catarinense - constata-se que:

O ethos é a morada do animal e passa a ser a "casa" (oikos) do ser humano, não já a casa material que lhe proporciona fisicamente abrigo e proteção, mas a casa simbólica que o acolhe espiritualmente e da qual irradia a própria casa material uma significação propriamente humana, entretecida por relações afetivas, éticas e mesmo estéticas, que ultrapassam suas finalidades puramente utilitárias e a integram plenamente no plano humano da cultura (VAZ. 2002, p. 40).

Contudo, a constituição desse existir ético; dessa integração plenamente humana no âmbito cultural, no Oeste catarinense, pouco se destacou nos documentos históricos, pois, essa região sempre 
esteve ausente das políticas públicas e, das pesquisas científicas. São poucos os escritos que se tem acerca da historicidade do Oeste de Santa Catarina. Ora, a própria terminologia "oeste catarinense passou a ser utilizado, mais especificamente, depois do acordo de divisas entre Santa Catarina e Paraná, celebrado em 1916" (CHITOLINA, 2013, p. 23). Nessa mesma perspectiva, a autora menciona que nos estudos de documentos dessa região, sobretudo nos mapas espanhóis e portugueses, se denominavam "terra de ninguém", "sertão desconhecido" entre outros.

Outros poucos registros históricos se configuram primeiramente na própria vinda do primeiro governador, Adolfo Konder, a essa região, em 1929, "muito tempo depois de ter sido conquistada pelos catarinenses" (POLI, 2006, p.169). Além disso, (CHITOLINA, 2013, p. 23) volta a salientar as denominações dessa expedição: "vasto deserto, paraíso da criminalidade, região inculta e desconhecida, zona do banditismo, confins do estado, sertões, sertão bruto". Tornando-se complexa a desconstrução dessas denominações, pois, na conceitualização filosófica do ethos, jamais se encontraram essas terminologias negativas no âmbito cultural de um povo. Pelo contrário, o ethos "trata-se de um legado - o mais precioso - que as gerações se transmitem (trandere, traditio) ao longo do tempo e que mostra, por outro lado, uma não menos extraordinária capacidade de assimilação de novos valores e de adaptação a novas situações" (VAZ, 2002, p. 40).

Ora, nessa dimensão de assimilar novos valores, - "a universalização do ethos se desdobra e particulariza em ethos econômico, ethos político, ethos social propriamente dito" (VAZ, 2004, p. 22), acenando-nos para a reflexão acerca do ethos da comunidade familiar no Oeste catarinense. Por conseguinte, toda essa modificação social entre as classes sugere-nos um olhar crítico sobre as novas configurações familiares, pois a "Grande Família" se submetia aos trabalhos agrícolas, transformando a natureza em produção de grãos e desenvolvendo as atividades da pecuária e da suinocultura. Portanto, a formação do ethos no Oeste Catarinense acaba passando por transformações significativas - as práticas de uma agricultura da subsistência são deixadas de lado e surgem novas atividades agrícolas voltadas ao mercado. (RELATÓRIO DE PESQUISA, 2012, p.8 ).
Além do que, no pensar vaziano, a complexidade do ethos se dá na ênfase aos "hábitos no próprio indivíduo e, na sociedade, os costumes e normas das esferas particulares nas quais se exercerá sua práxis, ou seja, trabalho, cultura, política e convivência social" (VAZ, 2004, p. 23). oportunizando-nos articular deste modo o ethos da educação, como pressuposto básico da tradição, do hábito (hexis) tornando-se "no indivíduo, forma permanente de seu agir pela educação - a historicidade do hábito" (VAZ, 2002, p. 42).

Ora, nessa dimensão de abertura das ações humanas na tradição, Renk (2004, p. 43) pontuará que é neste contexto que o jovem não vê mais perspectivas de continuidade na agricultura familiar fechada como no período anterior. Isso porque, diante "à crise vivenciada a partir dos anos 70 , o anseio de permanência e de continuidade mobilizavam a todos os membros familiares, fazendo com que muitos jovens deserdados sentissem-se excluídos de sua condição camponeses".

Outro dado importante, que passou a ser constituído nesse processo mercadológico, encontrase na implantação industrial - o surgimento dos grandes frigoríficos - que passaram a fazer parte da formação do ethos regional, contribuindo significativamente com a saída de muitos migrantes do campo em busca de melhores condições (RELATÓRIO DE PESQUISA, 2012, p. 8). Com essa dinâmica no tecido social, o ethos regional com o êxodo rural apresentou-nos diferenças bruscas no âmbito familiar. Não mais prevaleceu a ideia de uma família grande para mão de obra. Deste modo, a partir do século XXI, com as novas configurações, as famílias passam a ser pequenas e os pais trabalham fora, deixando seus filhos aos cuidados da educação do Estado (RELATÓRIO DE PESQUISA, 2012, p. 9). Inclusive, nesse processo de transformação entre o ethos familiar e do trabalho no Oeste catarinense - é viável refletir acerca da construção de um ethos do direito, pois, na Constituição Federal Brasileira de 1988, sobretudo nos artigos 205 a 208, está determinada uma nova estruturação no âmbito da educação - inferindo que todos deverão ter direito ao acesso à Escola, sendo, então, direito e dever do Estado essa garantia de uma educação pública, gratuita e, além disso, essa educação formal deve ser constituída e oferecida sob o prisma de padrões mínimos de qualidade. 


\section{Sob a Égide do Estado e do Capital, surge um novo Ethos}

O caráter coletivo e comunitário das colonizações do Oeste de Santa Catarina (Brasil) foi condição necessária para a reprodução da família camponesa na primeira metade do século XX. A visão holística do meio, em que o conjunto e o todo se encontram ligados inextricavelmente, inscreve-se, em última análise, no modelo estacionário a que o colonizador foi submetido. Essas "ilhas de ocupação", atormentadas e extasiadas com doenças epidêmicas, tiveram de conjugar esforços que, necessariamente, passavam pela solidariedade horizontal. A solidariedade constituiu uma blindagem contra a insegurança e a instabilidade e, em última instância, condição necessária para a sobrevivência do próprio tecido social.

Na genealogia dos valores da vida pioneira, o zelo pela vida comunitária constituiu-se num valor supremo. Em prol da filantropia comunitária, a vida privada era sacrificada sem titubear. "A fraternidade solda a comunidade", afirma Morin (2003, p.124). Na vivência comunitária, as engrenagens administrativas e as bases filosóficas e ideológicas, invariavelmente, eram assumidas pelos líderes e o clero que, graças à sua influência, conseguiu drenar para a Educação grande parte das economias da população:

A formação de uma comunidade religiosa sempre vinha acompanhada da instalação de uma escola. Desde os primórdios da colonização, os imigrantes teutos zelavam por uma instituição que se tornou característica das suas comunidades rurais, a escola paroquial ou comunitária. Tornou-se uma instituição singular, com mérito de suprir a ausência inicial das escolas públicas (PAIVA, 2003, p.83).

O professor, com suas múltiplas funções (culturais, políticas, religiosas e sociais), foi um personagem estratégico para a aglutinação dos migrantes e para a imposição de normas estabelecidas pelo clero, mesmo que suas ações fossem por vezes tempestuosas, recriminatórias e didaticamente condenáveis. Deste modo, o arcabouço das relações próprias de cada uma das colônias, com o mínimo de intercâmbio externo, exigia cooperação entre as famílias. Os mutirões suprimiam as limitações individuais. A máxima das sociedades arcaicas "dar é receber" assume aqui todo o seu significado. A exemplo dos Parceiros do Rio Bonito, de Antonio Candido, também, nas colonizações organizadas, a obrigação moral do beneficiário em atender aos chamados eventuais dos que o auxiliaram perpetuou essa forma de solidariedade:

A necessidade de ajuda imposta pela técnica agrícola e a sua retribuição automática determinava a formação duma rede ampla de relações, ligando uns aos outros os habitantes do grupo de vizinhança e contribuindo para a unidade estrutural e funcional (CANDIDO, 2003, p.89).

O isolamento da região provocou condicionamentos adaptativos. Uma multiplicidade de técnicas locais, geradas espontaneamente, movia os "pioneiros". Todas as famílias eram potencialmente produtoras de alimentos, objetos de trabalho, roupas, calçados, móveis e outros. Do mercado longínquo e afastado, uma vez e outra eram adquiridos alguns produtos impossíveis de extrair da natureza local. A necessidade fez aflorar a criatividade das pessoas. Inventaram-se moinhos, prensas, rodas d' água, instrumentos de trabalho, cachaça, vinho, cerveja. Nos meandros da colonização, gestavam-se cientistas naturais, mecânicos, construtores, sapateiros, costureiras, farmacêuticos, parteira... "Na aurora dos tempos históricos, o homem dependia diretamente do espaço circundante para a reprodução de sua vida. Era necessário conhecer seus segredos para sobreviver", afirmava Milton Santos (2003).

Famílias desestabilizadas por doenças ou catástrofes eram socorridas, tendo em vista o caráter funcionalista da comunidade. Patologias resolvidas com intuito de restituir o membro ao corpo social único. Freud (1990), nas suas análises sociais, afirma que quanto mais o indivíduo inclui-se numa formação coletiva, mais ele será contido num jogo de obrigações e trocas. Já Lévy (1998, p. 37) afirma:

A hospitalidade é um sustentáculo do laço social. O laço social é concebido segundo a forma de reciprocidade: o hóspede é tanto aquele que recebe como o que é recebido. E cada um deles pode se tornar estrangeiro. A hospitalidade assegura a possibilidade de viajar, de encontrar o outro em geral. Pela hospitalidade, aquele que é separado, diferente, estranho, é acolhido, integrado, incluído em uma comunidade. A hospitalidade consiste em atar o indivíduo ao coletivo. Contrapõe-se inteiramente ao ato de exclusão. 
As pequenas comunidades são locais centrípetos, na versão de Antonio Candido (2003), de vida social e cultural mais rica, favorecendo a convergência de pessoas em atividades comuns. Esparsos em grupos ralos e disseminados por uma extensão imensa, o projeto comunitário, com sua força religiosa, foi um fator de sociabilidade e de sobrevivência do próprio grupo. Desse modo, torna-se mais fácil de entender as pequenas propriedades, as práticas da policultura, a autossuficiência, as roças comerciais locais eram as marcas econômicas da região. A criação dos animais era nomeadamente caseira, sem padrões tecnologicamente dados. A vida se dava mais ou menos ao estilo do que Bauman (2003, p.07) define de comunidade:

[...] Numa comunidade, todos nos entendemos bem, podemos confiar no que ouvimos, estamos seguros a maior parte do tempo e raramente ficamos desconcertados ou somos surpreendidos. Nunca somos estranhos entre nós. Podemos discutir - mas são discussões amigáveis, pois todos estamos tentando tornar nosso estar juntos ainda melhor e mais agradável do que até aqui e, embora levados pela mesma vontade de melhorar nossa vida em comum, podemos discordar sobre como fazê-lo. Mas nunca desejamos má sorte uns aos outros, e podemos estar certos de que os outros à nossa volta nos querem bem. [...] E ainda: numa comunidade podemos contar com a boa vontade dos outros. Se tropeçarmos e cairmos, os outros nos ajudarão a ficar de pé outra vez. Ninguém vai rir de nós, nem ridicularizar nossa falta de jeito e alegrar-se com nossa desgraça. Se dermos um mau passo, ainda podemos nos confessar, dar explicações e pedir desculpas, arrepender-nos se necessário; as pessoas ouvirão com simpatia e nos perdoarão, de modo que ninguém fique ressentido para sempre. E sempre haverá alguém para nos dar a mão em momentos de tristeza. Quando passarmos por momentos difíceis e por necessidades sérias, as pessoas não pedirão fiança antes de decidirem se nos ajudarão; não perguntarão como e quando retribuiremos, mas sim do que precisamos.

Em muitas situações o sociólogo fala de comunidade com outros parâmetros e contextos. No entanto, todos esses elementos são enriquecedores para discutir as transformações regionais nos mais diversos aspectos. Milton Santos (2001, p. 36) escreve que o uso extremado das técnicas e a proeminência do pensamento técnico conduzem à necessidade obsessiva de normas. Essa pletora normativa é indispensável à eficácia da ação. Como, porém as atividades hegemônicas tendem a uma centralização, consecutiva à concentração da economia, aumenta a inflexibilidade dos comportamentos, acarretando um mal-estar no corpo social. Este mal-estar pode ser percebido na Região Oeste de Santa Catarina, a partir dos anos 1970, quando entra nos circuitos nacionais e internacionais da economia (Revolução Verde).

O desenvolvimento dos meios de comunicação, a interação com outros espaços, a preocupação do Estado e, ainda, o fascínio do capital (agroindústrias) pela região na qual pudesse espalhar seus interesses implantaram a denominada modernidade tecnológica. A interação cultural e econômica transformou o espaço engessado e fechado. A entrada mais agressiva do capitalismo destituiu o poder religioso e os laços de solidariedade que soldavam até então o tecido social.

A modernização, introduzida em toda a região Oeste de Santa Catarina a partir da década de 1970, transformou o "espaço natural" e rompeu com a sociabilidade tradicional, integrando a região aos circuitos internacionais da economia. As grandes agroindústrias (leite, aves e suínos) colocam-se como centrais irradiadoras da modernidade da região e implantam relações artificiais no campo. Para o capital, passa a haver uma dualidade na região: de um lado, os empreendedores do movimento, da fluidez, da oxigenação, da instabilidade, da racionalização; de outro lado, os considerados como inadequados aos padrões de produtividade e competitividade. As empresas hegemônicas, além da modernização das atividades agrícolas, redirecionaram drasticamente a forma de vida de suas populações. Agem sobre uma parcela do território e governam por metas. As metas e os prêmios contagiam, classificam, excluem, humilham e criam o espetáculo da denúncia.

A competitividade destroçou antigas solidariedades horizontais e implantou a verticalidade. "Nexos verticais se superpõem à compartimentação horizontal, característica da história humana até data recente" (SANTOS, 2001, p.84). Essas empresas, a partir do seu epicentro de atuação, mudam as formas de ser e de agir. Quebram resistências, fidelidades, sequestram autonomias, potencializam vocações 
e impõem velocidades. O jogo da vida renasce de um contexto, novos personagens e nova correlação de forças. As novas regras criam novos espaços, difundem novas verdades estabelecem novos laços e novas identidades.

O mundo opera e se move pelas mudanças, nada é perene e tudo é efêmero dirão os "pilotos da História". O caráter da mudança vai redefinindo ao longo dos séculos os papéis sociais do mundo do trabalho, entre os quais o do professor. Papéis estes, definidos, cada um no seu devido tempo ou ao mesmo tempo, por reis, papas, homens de negócio, mídia e tantos outros pilotos do bem e do mal. Espaço onde o caminho da vida pode ser o da liberdade, da inclusão e de respeito ao diferente, desde que o conhecimento não se faça cético e a inteligência não se torne empedernida. A inteligência humana já foi utilizada para levantar muralhas do ódio e morticínios, mas também para chamar apelos de fraternidade humana. Como afirma (Morin 2005, p. 224) "a história desafia qualquer predição. Seu devir é aleatório, sua aventura sempre foi, sem que se saiba, mas agora se deveria saber, uma aventura desconhecida".

A globalização da economia mundial juntamente com a ascensão dos meios de comunicação de massa, aliados do zeitgeist, e as desconstruções levantadas por filósofos, sociólogos e historiadores descortinam um novo momento histórico, momento esse que tende a romper, provisória ou completamente, os paradigmas que sobreviveram incólumes por séculos. Partindo do local para o global e vice-versa, temos como novo paradigma existencial o mundo, que agora cabe em nossas mãos, mas ao mesmo tempo o seu peso, quando não é mais permitido fingir que não estamos diretamente envolvidos com suas metamorfoses e transformações:

Uma das características distintivas da modernidade é uma interconexão crescente entre os dois extremos da extensionalidade e da Intencionalidade: de um lado influências globalizantes e, de outro, disposições pessoais. Quanto mais a tradição perde terreno, e quanto mais reconstitui-se a vida cotidiana em termos da interação dialética entre o local e o global, mais os indivíduos veem-se forçados a negociar opções de estilos de vida em meio a uma série de possibilidades. O planejamento da vida organizada reflexivamente torna-se característica fundamental da estruturação da auto identidade. (CASTELLS, 2002, p. 27).
Desse modo, as pesquisas no âmbito das ciências sociais e humanas estão se aprofundando nas transformações do mundo atual. Como vimos, temos mais perguntas que respostas, consequentemente, os estudos e teorizações sobre o novo espírito do tempo é mais de compreensão do que de explicação. Cabe-nos entender o que se passa com os sistemas simbólicos de subjetivação dos indivíduos contemporâneos, entender as formas de relacionar-se consigo e com o outro, de entender como são consumidos os produtos dos mass media e como esses elementos repercutem na vida humana presente e futura. E por último, mas não menos importante, entender como se dá o processo de formação educacional desses indivíduos.

\section{Um Ethos sem Exclusão é possível no século $X X I$}

Retroceder à trajetória tecnológica a qual a sociedade moderna está imersa é algo utópico. Se não há caminho inverso, o paradigma consiste em ajustar a capacidade ecossistêmica da natureza ao modelo capitalista. No final do século XX e primeira década do século XXI, entre tantas questões pertinentes ao desenvolvimento econômico/industrial/ tecnológico da Região Oeste de Santa Catarina, o desenvolvimento somente seria possível mediante a utilização predatória dos recursos naturais.

O caráter espoliativo dos recursos naturais da região (florestas, água, solo e outros) verificado após a implantação da agricultura técnico-científica, deve suscitar preocupação. A "Mãe Terra" ainda beneficia a maioria da população Oestina? Ou para a maioria das comunidades locais resta as mazelas do desenvolvimento econômico?

Com consequência desse arranjo, a comunidade tornou-se sociedade, a identidade, em identidades e o navio da globalização lança âncoras. Um processo de distanciamento entre os membros das comunidades vai se acentuando. Aqui nos remete a Tonnies (1947) e Bauman (2003), que em linhas gerais concordam com a ideia de que em comunidades as relações entre seus membros se dão de modo autêntico, por outro lado, a dissolução das comunidades em sociedades mostra relações menos legítimas, as relações face a face tendem à diminuição. Desse modo, Tonnies (1947, p.41) postula o que seriam 
as regras gerais da comunidade: a) parentes, cônjuges, vizinhos e amigos se gostam reciprocamente; b) entre os que se gostam, há consenso; c) os que se gostam, se entendem, convivem e permanecem juntos, ordenam sua vida em comum. Para Bauman, a comunidade seria o lugar aconchegante, onde todos sabem quem são seus membros e as ideias são recíprocas para o bem comum.

A favor da sedutora ideia de aldeia global, uma espécie de consciência coletiva toma conta das localidades tendo em vista a possibilidade do contato total com o globo. Nesta dinâmica, há possibilidade de regenerar uma consciência coletiva do tipo durkheimiana? Uma consciência agregadora, solidária e autorreferente?

Acredita-se, deste modo, na possibilidade de escolha e resistência. Entretanto, isso só será possível compreendendo, analisando e explicando a parte que nos cabe, ou seja, o espaço geográfico e sociocultural no qual estamos inseridos. Os estudos em torno da globalização e seus efeitos estão longe de chegar num denominador comum. Bauman (2008, p.48) afirma que "todos estamos fadados a contragosto ou não aos desígnios da globalização". Por sua vez os processos globalizantes penetraram e penetram a Região Oeste de Santa Catarina, transformando o modus vivendi da população - modo de vida construído com base na solidariedade e no viver comunitário. Haveria possibilidades de reaglutinamento de uma população separada e compartimentada por um processo produtivo?

A visão unilateral do processo de globalização é refutada por Haesbaert (2007) quando vislumbra a possibilidade de uma sociedade global no sentido positivo, e não apenas negativo, de opressão e controle. Conforme o autor (2007, p, 50):

Simbolicamente, territórios como aqueles das reservas naturais e patrimônios da humanidade podem ajudar na consolidação de uma identidademundo, capaz de unir numa mesma "redeterritório" toda a civilização planetária, que pela primeira vez (desde a Segunda Grande Guerra) coloca em risco sua própria existência na superfície da Terra.

$\mathrm{Na}$ leitura do autor, uma nova territorialidade emerge nas entranhas da globalização. Entre as características que regem a emergência destas novas territorialidades deve-se considerar, novas identida- des e coletividades que são criadas e movidas, graças às tecnologias e os meios midiáticos disponíveis para grande parte da população regional.

No espaço regional do Oeste de Santa Catarina, já se pode notar - na segunda década do século XXI - que o poder nivelador da globalização não conseguiu uma passiva adequação de todos aos produtos culturais. Grupos dissidentes fazem recortes claros no tecido social único. Um jogo de forças, silenciosamente, atua contra o poder monopolizador da massificação Cultural e econômica. Exíguas minorias perseguem de modo incontestável, um mundo substancialmente autônomo.

Por conseguinte, surgem cooperativas de produtores rurais, comercialização de produtos da agricultura familiar, produção de agroecológicos, movimentos regionais de resistência contra danos ambientais, convocações de atos públicos contra exploração de minorias, entre tantos outros, mostram a formação desse novo Ethos Oestino. Volta-se a um dos princípios básicos que orientou a perpetuação da raça humana: ela sobreviveu, porque sempre houver mais princípios de inclusão do que de exclusão.

\section{Conclusão}

Ao longo deste ensaio teórico, discorreu-se a respeito da formação dos povos nativos do Oeste de Santa Cantarina, pontuando-se que eles construíam ações de solidariedade, fraternidade e, sobretudo, de ajuda mútua na disseminação dos saberes em prol da transformação da natureza (physis) para a própria sobrevivência das comunidades. Portanto, esse modo de ser constituiu-se o próprio ethos dos nativos daquela época.

No entanto, como o ethos é constituído no espaço e tempo e, por conseguinte, passa por transformações, com a chegada dos migrantes, a cultura nativa sofreu um forte impacto, caracterizando-se como de ordem ontológica. Isso porque causou uma ruptura na cultura de subsistência a fim de implantar uma cultura mercantilista, ou seja, de transformação da natureza em lucro e não mais de apropriação dela, como a mãe natureza (Gaia) que protege e cuida fornecendo os alimentos para a sobrevivência da comunidade.

Com a chegada dos migrantes de origem europeia, que já haviam vivenciado a ascensão 
capitalista na Europa, o ethos oestino tomou outra forma. Dado o isolamento da região, uma trama de relações se entrelaçaram e se sustentaram no espaço ocupado. A solidariedade foi condição necessária para a sobrevivência destes migrantes. Os novos protagonistas, invariavelmente, empreenderam uma peregrinação para a formação de comunidades abnegadas, humildes e altruístas. E, para atingir tal intuito, tiveram que modelar a vida social, o amor, o trabalho e o lazer pelo coletivo. Houve poucos pontos de oposição, conflito e contradição no interior da colonização.

Por sua vez, a partir da década de 1970, as políticas públicas no espaço agrário, o avanço dos meios de comunicação e de transportes desagregou, de múltiplas maneiras, algumas explicitamente brutais, o padrão cultural e social deveras homogêneo. A funcionalidade do modelo de desenvolvimento que o capital desenhou para a região demoliu as bases de uma sociedade, até então, bastante virtuosa e horizontal.

\section{Referências}

BAUMAN, Zygmunt. Globalização: as consequências humanas, Rio de janeiro: Zahar, 1999.

Comunidade: a busca por segurança no mundo atual, Rio de Janeiro: Zahar, 2003.

. Medo líquido, Rio de Janeiro: Zahar, 2008.

BOFF, Leonardo. Ethos mundial: um consenso mínimo entre os humanos. - Rio de Janeiro:Sextante, 2003.

Caracterização geral da mesorregião Oeste de Santa Catarina. Anderson Luiz Tedesco et al. Joaçaba: UNOESC, 2012. 44 p. Relatório parcial 2011 da pesquisa "Indicadores de Qualidade do Ensino Fundamental na Mesorregião Oeste de Santa Catarina: estratégias ações na rede pública municipal de ensino (2010-2014)" Vinculada ao Programa Observatório da Educação/Capes. Joaçaba,SC, 2012.

CASTELLS, Manuel. A sociedade em rede. A era da informação: economia, sociedade cultura. São Paulo: Paz e Terra, 2002.

CANDIDO, Antonio. Parceiros do Rio Bonito. 10. ed. São Paulo: Editora 34, 2003.

CHITOLINA, Valdirene. Velho Xaxim: a colonização da antiga fazenda Rodeio Bonito (1920-1954) - Xanxerê: News Print, 2013, 308 p.

DURKHEIM, E. Regras do método sociológico. São Paulo: Nacional, 1995.
FREUD apud ENRIQUEZ. Da horda ao Estado. Rio de Janeiro: Jorge Zahar, 1990.

HAESBAERT, Rogério. O território em tempos de globalização. Revista Eletrônica Etc., espaço, tempo e crítica. $\mathrm{N}^{\circ}$ 2(4), VOL. 1, 15 de agosto de 2007.

HERMANN. Nadja. Educ. Soc., Campinas, vol. 29, n. 102, p. 15-32, jan./abr. 2008

LÉVY, Pirre. A inteligência coletiva: por uma antropologia do ciberespaço. São Paulo: Edições Loyola, 1998. Tradução de Luiz Paulo Rouanet.

MORIN, Edgar. O Método 5: A Humanidade da Humanidade, a identidade humana. 2. Ed. Porto Alegre: Sulina. Tradução de Juremir Machado da Silva, 2005.

MORIN, Edgar. O Método 5: A Humanidade da Humanidade, a identidade humana. ${ }^{\text {a }}$. edição, Porto Alegre: Sulina, 2003. Tradução de Juremir Machado da Silva.

PAIVA, C. Escolas de língua alemã no Rio Grande do Sul: o nazismo e a política de nacionalização. In: FIORI, N. A. (Org.). Etnia e educação: a escola "alemã" do Brasil e estudos congêneres. Florianópolis: Ed. da UFSC; Tubarão: Editora Unisul, 2003.

POLI, Jaci. Caboclo: pioneirismo e marginalização. In: Centro de Organização Sócio-Cultural do Oeste: 20 anos de memória e história no oeste de Santa Catarina. Chapecó: Unochapecó, 2006, p. 169.

RENK, Arlene; SAVOLDI, Adiles. Contestado: tropos, roteiros, imagens, linguagens. Cadernos do CEOM, Chapecó v. 17, n. 20, dez. 2004.

SANTOS, Milton. Por uma outra globalização. Rio de Janeiro: Record, 2001.

SANTOS, Milton. Economia espacial; críticas e alternativas. São Paulo: Edusp, 2003.

STRECK, Danilo Romeu. O éthos de uma educação humanizadora. Espaço Pedagógico, Passo Fundo/RS, v. 13, n.1, p. 95-106, 2006.

TÖNNIES, Ferdinand. Comunidad y Sociedad. Buenos Aires: Losada, 1947.

VAZ, Henrique de Lima. Escritos de filosofia IV: introdução à ética filosófica I. 2. ed. São Paulo: Loyola, 2002.

Ética e cultura. 4. ed. São Paulo: Loyola, 2004.

WOLOSZYN, Noeli. Em busca da terra: colonização e exploração de madeiras no Oeste Catarinense. 2007. Disponível em: < http://www.pesquisa.uncnet.br/ pdf/historia/BUSCA_TERRA_COLONIZACAO EXPLORACAO_MADEIRAS_OESTE_CATARINENSE. pdf. $>$. Acesso em: 27 ago. 2012.

Submissão: $12 / 08 / 2013$

Aprovação: 09/2014 